\title{
Assessing the innovative capacity of the scientific-industrial complex
}

\author{
Andrey Gorbachev ${ }^{1, *}$, and Tatiana Fedorova ${ }^{2}$ \\ ${ }^{1}$ Instrument Design Bureau named after Academician A. Shipunov - Tula JSC, 300001, 59 \\ Shcheglovskaya Zaseka str., Tula, Russia. \\ ${ }^{2}$ Komi Republican Academy of State Services and Management, 167000, 11 Kommunisticheskaya \\ str., Syktyvkar, Russia.
}

\begin{abstract}
One of the most effective structures on release of innovative products is the scientific-industrial complex today. To make innovative products for the establishment of capability of scientific-industrial complex and to perform competitive activity, such characteristic of the enterprise as its innovative potential having three following components is estimated: the volume of the resources of the enterprise used for performance of works, an opportunity to perform profitable works and to perform investing activities by means of implementation of orders with remote financial result. Efficiency of activity of scientific-industrial complex depends on capability of the enterprise competently to distribute the potential between different job groups, providing financial result, both today and in the future.
\end{abstract}

Economies of the leading countries of the world, such as the USA, China, Japan, Russia, define efficiency of development of the economies in many respects by means of mass use of innovative goods. Budgetary appropriations in 2016 on researches and product developments of civil appointment respectively make: the USA - 62,7 billion a dale., China - 59,1 billion a dale., Japan - 33,1 billion a dale., Russia - 18,5 billion a dale. [1]. Therefore, there is a high interest in states and businesses in the organization of an effective production process of innovative goods. One of such structures is the scientific-industrial complex (further SIC) performing creation of innovative products by means of carrying out applied research, developmental and production works. For maintenance of the competitiveness of SIC, it is necessary to analyze results of development of fundamental sciences, as well as results of its activity, to timely consider reaction of final consumers to products, and to timely react to changes of trends in the market and state of the economy.

The production of SIC is performed within the applied research works by means of collecting the work requests submitted in the form of orders [2]. Sources of forming of requests are: (a) third parties, such, as: enterprises, organizations, research institutions, government institutions, venture funds and other; (b) the initiative developments of SIC based on own analysis of the enterprise of requirements of the market and a possibility of their satisfaction with determination of a financing source.

* Corresponding author: merc123@mail.ru 
For the establishment of opportunities of the enterprise to perform works of NPK, it is important to estimate the innovative potential and to understand the greatest possible volume of innovative works, which the enterprise can execute, according to the available resources [3].

It is reasonable to carry to the SIC the following resources: (a) the engineering procedures representing technical and technology solutions, which logical chain allows to produce innovative products; (b) the personnel of the corresponding number and qualification, which are carrying out necessary works; (c) the equipment and the machine base including required type of rooms for the placement and allowing to carry out works; and (d) financial resources as the volume of the means demanded for work by request.

Besides, the traditional resources allowing to perform release of earlier developed products and the innovative resources allowing to implement innovative projects are of great importance. So, engineering procedures and the machine base can be referred to traditional resources on formal grounds, and financial resources, research instrument base and the personnel which are engaged in developments and researches to innovative resources. The personnel performing research activities not only makes a part of innovative potential of the SIC, but is the basic element creating the competitive enterprise level.

For the analysis and creation of effective activity of the SIC, it is necessary to consider a ratio of innovative and traditional resources in a total amount of capacity of the enterprise.

Generally, the SIC plans activities according to an opportunity to implement the orders, which are the main source of profit for the enterprise [2]. Besides, it is necessary to consider that some orders can be implemented by the SIC within one year, others - within three or five years. As a result, planning of SIC activities and assessment of its potential are performed within a certain financial period. As a rule, a period in one year is typically used.

Therefore, the important characteristic of the order is the "remoteness" of obtaining financial results. If the terms of order fulfillment are longer, than the period during which the planning of SIC's activities and assessment of its potential is performed is longer. Therefore, similar works can be carried to investments with remote result.

The remote result of implementation of the order can be considered as result from investing activities as investments of costs in such projects allow to accumulate the asset cost of the enterprise.

Also, an important factor in the analysis of the order is accounting of a possibility of "change" of the SIC resources. It is necessary to understand opportunities that would significantly influence the SIC resources: (a) to increase or reduce the volume of the resource available for the enterprise; (b) modernizing a particular resource; (c) introducing a new resource.

Implementation of the orders that change the structure of the SIC resources is performed for the purpose of a possibility for the enterprise to perform more profitable and urgent works afterwards. Also, it is responsible for maintaining the quality of the performed processes at the competitive level, according to the tendencies of development of the market and scientific and technical progress.

While following certain innovative goals and reaching the potential of the SIC, an enterprise can execute, at the same time, a number of orders, allowing to get profit in the period of assessment, and also the orders allowing to gain effect in the future, that is the orders with a "remote" financial result. At the same time, the potential of the SIC is distributed between the orders providing financial result in the estimated period of activity of the enterprise and the orders having a "remote"/"delayed" financial result.

As a result, the SIC potential can be estimated by the three following criteria:

1. The volume of the resources which are available to the enterprise.

2. The volume of the works performed by an enterprise allowing to receive financial results in the estimated period. 
3. The volume of the works performed by the enterprise allowing to receive financial results in the subsequent periods of activity.

In the latter case, results of assessment should be given to the considered period of activity of the enterprise.

The main feature in the work of SIC is connected to the simultaneous accomplishment of orders bringing revenues in a current period, as well as those researches who can follow orders and, respectively bring income in the future. As a result a main objective in managing the SIC structures is the establishment of a balance between traditional and innovative resources, creating thereby conditions for gradual reforming of the activities for achieving the competitiveness level meeting the requirements and tendencies of the development of scientific and technical progress performed by the enterprise.

\section{References}

1. Russian Academy of Sciences, Investing in science: towards a knowledge economy. (Presidium of the Russian Academy of Sciences, Moscow, 2016)

2. E. A. Fedorova, Y. A. Gorbachev, Bulletin of the Research Center of Corporate Law, Management and Venture Investment of Syktyvkar State University, 4 (2017)

3. E. A. Fedorova, Y. A. Gorbachev, UGUID Bulletin, 79, 2 (2017)

4. T. A. Fedorova, The formation of the cost of innovation-active enterprises: monograph (Lidar-Art, Tula, 2010)

5. A. Damodaran, Investment valuation: Tools and techniques of assessment of any asset (Alpina Business Books, Moscow, 2004) 